\title{
Influence of Thermal Treatment on Frequency Dependence of the Switching Field in Amorphous and Nanocrystalline FeNiMoB Microwires
}

\author{
E. Komova ${ }^{a, *}$, R. VARGA ${ }^{b}$ And M. VAzQUez ${ }^{c}$ \\ ${ }^{a}$ Faculty of Aeuronautics, Technical University of Košice, Rampová 7, 04121 Košice, Slovakia \\ ${ }^{b}$ Institute of Physics, Faculty of Science, UPJŠ, Park Angelinum 9, 04154 Košice, Slovakia \\ ${ }^{c}$ Instituto de Ciencia de Materiales de Madrid, CSIC, 28049 Madrid, Spain
}

\begin{abstract}
Amorphous and nanocrystalline ferromagnetic glass-coated microwires show excellent magnetic properties that make them very suitable to be employed as sensing elements in devices for technical applications. New $\mathrm{Fe}_{40} \mathrm{Ni}_{38} \mathrm{Mo}_{4} \mathrm{~B}_{18}$ alloy composition can be appropriate to prepare soft magnetic nanocrystalline microwires which exhibit magnetic bistability even in the nanocrystalline state. Stability of magnetic properties after different thermal treatments $\left(T_{\mathrm{a}}=250-425^{\circ} \mathrm{C}\right)$ and after nanocrystallization was confirmed by the switching field $H_{\mathrm{sw}}$ measurements. The frequency dependence of the switching field was investigated. Two contributions to the domain wall switching mechanism were recognized: magnetoelastic one coming from the magnetoelastic interaction of the magnetic moments with the stresses and relaxation one coming from the structural relaxation of local defects at atomic scale. But, the relative role of both contributions has been shown to vary strongly in different stage of devitrification.
\end{abstract}

PACS numbers: 75.50.Kj, 75.60.Ej, 75.50.Tt

\section{Introduction}

The nanocrystalline microwires (MWs), prepared by the heat treatment from amorphous precursors, have been subject of many studies starting from Finemet based MWs [1, 2]. The nanostructured Finemet, produced in ribbon form, display excellent soft magnetic properties due to its two-phase nature with small $\alpha-(\mathrm{Fe}, \mathrm{Si})$ grains embedded in a residual amorphous matrix. However, the MWs undergo strong stresses during the annealing due to the different thermal expansion coefficient of the metallic nucleus and glass coating. As a result, a $\gamma$-Fe phase appears in the Finemet based MWs covered by the glass instead of the desired $\alpha-(\mathrm{Fe}, \mathrm{Si})$ phase. The $\gamma$-Fe phase is non-magnetic and deteriorates the soft magnetic properties of MWs [3]. In order to solve this problem, amorphous MWs of nominal composition $\mathrm{Fe}_{40} \mathrm{Ni}_{38} \mathrm{Mo}_{4} \mathrm{~B}_{18}$ can be used to prepare nanocrystalline MWs. Subsequent heat treatment produces a ultrafine grain structure of $\gamma-(\mathrm{Fe}, \mathrm{Ni})$ grains sizes of typically $10 \mathrm{~nm}[4,5]$. Therefore, the $\gamma-(\mathrm{Fe}, \mathrm{Ni})$ phase is ferromagnetic in contrary to the $\gamma$-Fe one, $\mathrm{Fe}_{40} \mathrm{Ni}_{38} \mathrm{Mo}_{4} \mathrm{~B}_{18}$ alloy is a perfect candidate for preparation of the soft magnetic nanocrystalline MWs with positive magnetostriction. Such MWs exhibit bistability even in the nanocrys-

* corresponding author; e-mail: eva.komova@tuke.sk talline state, which is interesting for many technical applications at $\mathrm{AC}$ fields and, therefore, it is very important to know frequency dependences of magnetic properties of these materials.

\section{Experiment}

The correlation between a structure change and the frequency dependence of switching field $\left(H_{\mathrm{sw}}\right)$ in annealed MWs was investigated. The study has been performed on glass-coated MWs with nominal composition $\mathrm{Fe}_{40} \mathrm{Ni}_{38} \mathrm{Mo}_{4} \mathrm{~B}_{18}$ prepared by the Taylor-Ulitovsky method. The diameter of the metal core was $8 \mu \mathrm{m}$ and the total diameter $12 \mu \mathrm{m}$. Pieces of microwire $7 \mathrm{~cm}$ long were taken for measurements by induction method [6] within the frequency range $10-3000 \mathrm{~Hz}$ with triangular waveform. Annealing was carried out at $350^{\circ} \mathrm{C}, 375^{\circ} \mathrm{C}$, $400{ }^{\circ} \mathrm{C}$ and $425^{\circ} \mathrm{C}$ during $1 \mathrm{~h}$.

Suitable annealing treatment leads to the optimal nanostructure and to the required magnetic behavior of the MWs. Microstructure of the annealed MWs was confirmed by X-ray diffraction [4]. Thermal behaviour of the structure corresponds to the structure of $\mathrm{Fe}_{40} \mathrm{Ni}_{38} \mathrm{Mo}_{4} \mathrm{~B}_{18}$ ribbons [5].

\section{Results and discussion}

Our measurement of the switching field value $\left(H_{\mathrm{sw}}\right)$ after different thermal treatment shows: at low frequen- 
cies $H_{\mathrm{sw}}$ decreases with increasing frequency and in the frequency range above $100 \mathrm{~Hz}$ the $H_{\mathrm{sw}}$ starts to increase (Fig. 1). This frequency dependence of the $H_{\mathrm{sw}}$ in amorphous and nanocrystalline MWs can be explained in terms of two contributions to the switching mechanism: a relaxation contribution and magnetoelastic contribution [6]:

$$
H_{\mathrm{sw}}=H_{\mathrm{sw}}^{p}+H_{\mathrm{sw}}^{\sigma} .
$$

The decrease of the $H_{\text {sw }}$ at low frequency can be satisfactorily explained in terms of magnetic after-effect. As a result of their preparation, the structure of amorphous wires is in metastable state and for this reason quite large relaxation effects can be expected. The relaxation contribution $H_{\mathrm{Sw}}^{p} \approx \frac{1}{M_{\mathrm{s}}}\left(1-\mathrm{e}^{-t / \tau}\right)$, associated with the structural relaxation, changes as a result of the change of the relaxation time $\tau$ which increases with the annealing temperature as a result of annealing out of the free space in the vicinity of the mobile defect. Therefore, the minimum in the frequency dependence of $H_{\mathrm{sw}}$ shifts to higher frequencies at higher temperatures (Fig. 1).

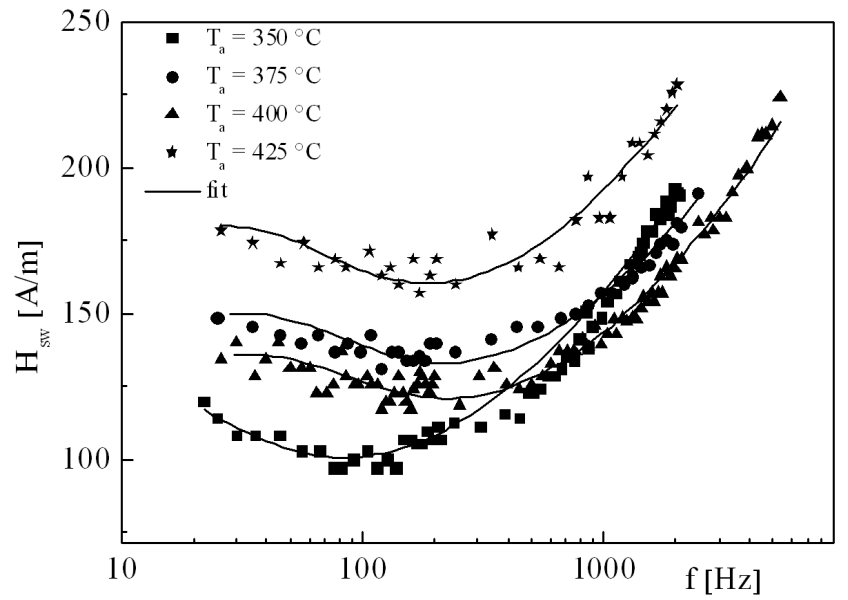

Fig. 1. Frequency dependence of the switching field of amorphous and nanocrystalline FeNiMoB microwires. Full lines represent the fit according to Eq. (1).

The magnetoelastic contribution $H_{\mathrm{sw}}^{\sigma} \approx f^{1 / n}$ [7] (where $n$ is a parameter ranging from 1 to 4 ) is arising from a magnetoelastic interaction of the magnetic moments with the internal stresses in the MWs. At the $350{ }^{\circ} \mathrm{C} n=3$, as it was found in the case of as-cast amorphous materials [8]. After nanocrystallization the $H_{\text {sw }}$ is less frequency dependent. Parameter $n$ increases to 4 and it remains at this value for all nanocrystalline states $\left(T_{\mathrm{a}}=375-425^{\circ} \mathrm{C}\right)$. Amplitude of magnetic relaxation contribution in nanocrystalline state decreases as it also was observed for other nanocrystalline materials [9].

\section{Conclusions}

The effect of annealing (at $350-425^{\circ} \mathrm{C}$ ) on the switching field of amorphous and nanocrystalline $\mathrm{Fe}_{40} \mathrm{Ni}_{38} \mathrm{Mo}_{4} \mathrm{~B}_{18}$ microwires has been studied. The observed dependences show the different values of $H_{\mathrm{sw}}$ after relevant thermal treatment (that leads to nanocrystallization), but the $H_{\mathrm{sw}}$ is very weak frequency dependent. This higher stability of switching field in the nanocrystalline microwires is very promising for various sensor applications.

\section{Acknowledgments}

The work was supported by the scientific grants VEGA 1/0076/09, 6RP/Manunet/UPJS and NanoCEXmat No. ITMS 26220120019.

\section{References}

[1] A. Zhukov, J. González, M. Vázquez, V. Larin, A. Torcunov, in: Encyclopedia of Nanoscience and Nanotechnology, Ed. H.S. Nalwa, American Scientific, New York 2004, Ch. 62, p. 365.

[2] H. Chirac, M. Tibu, Tibor-Adrian Óvari, IEEE Trans. Magn. 45, 4286 (2009).

[4] E. Komova, M. Varga, R. Varga, P. Vojtanik, J. Bednarcik, J. Kovac, M. Provencio, M. Vazquez, Appl. Phys. Lett. 93, 062502 (2008).

[5] R.V. Ramanujan, S.W. Du, J. Alloys Comp. 425 , 251 (2006).

[6] R. Varga, K.L. Garcia, A. Zhukov, M. Vazquez, P. Vojtanik, Appl. Phys. Lett. 83, 2620 (2003).

[7] A. Zhukov, M. Vázquez, J. Velázquez, C. Garcia, R. Valenzuela, B. Ponomarev, Mater. Sci. Eng. A 226-228, 753 (1997).

[8] E. Komova, M. Varga, R. Varga, P. Vojtaník, J. Torrejon, M. Provencio, M. Vazquez, J. Phys., Condens. Matter 19, 236229 (2007).

[9] L. Madej, G. Haneczok, A. Chrobak, P. Kwapulinski, Z. Stoklosa, J. Rasek, J. Magn. Magn. Mater. 320, e774 (2008). 